\title{
Investigation of Alardinskaya mine coal bumps causes using computer simulation of rock massif stress conditionals
}

\author{
Andrey Sidorenko, Vyacheslav Alekseev, Yury Sirenko \\ Saint Petersburg Mining University, 2, $21^{\text {st }}$ Line, Vasilievski Island, Saint-Petersburg, 199106, Russia
}

\begin{abstract}
The purpose of the paper was to identify the causes of rock bumps that occurred at the Alardinskaya mine (Russia) in 2011. The research was carried out using the finite element method. The developed three-dimensional model of the rock mass included a coal seam, rocks bedding above and below, goaf, and a system of local preparatory workings. The situation that arose immediately before the first rock burst was modeled during the research - when the longwall crossed a diagonal entry. The performed investigations enabled the authors to make a conclusion about a high danger of using technological schemes for the development of seams by longwalls leaving pillars that have a width less than the length of the support pressure zone, especially due to diagonal entries. As a safe technology for the longwall development of seams prone to rock bursts, it is recommended to apply a technological scheme with the abandonment of wide barrier pillars and four preparatory workings in each section, which has proven itself in the processing of rock bump hazardous seams in the state of Utah (USA).
\end{abstract}

\section{Introduction}

Coal is the most abundant energy resource in the world, and the coal industry, despite striving to decarbonize the world economy, remains an essential industry. Valuable grades of coal are usually mined underground. Elaboration of seams with longwall panels is the most effective technology for underground coal mining [1, 2], since the application of modern reliable and energyequipped facilities in longwalls provides high technical and economic performance of mines [3-5]. The Kuznetsk coal basin (Kuzbass) is the primary coal mining area in Russia. It is characterized by significant coal reserves lying in relatively favorable conditions for their production [6, 7]. However, a constant increase in the depth of mining in Kuzbass leads to a natural deterioration in mining conditions and a frequent growth of rock pressure manifestations, and the risk of accidents $[8,9]$. Almost all formations are threatened from a depth of $400 \mathrm{~m}$ by dynamic phenomena (rock bumps and sudden outbursts). The problem of rock bumps is relevant for all coal-mining countries of the world [1013]. Underground development of seams under the influence of several hazardous factors is characterized by the greatest complexity of conditions in the world [1416]. For instance, thick seam of the Tom-Usinsk region of Kuzbass are at the same time: methane-bearing; prone to spontaneous combustion; dangerous both in terms of rock bumps and sudden outbursts from a depth of $300 \mathrm{~m}$. Besides, the geodynamic hazard of mining operations is aggravated by the presence of thick solid layers of sandstone in the roof and soil of the developed seam.
The complexity of solving the problem of mining thick shallow seams prone to spontaneous combustion in conditions of geodynamic hazard is explained by the presence of conflicting requirements for the preparation and development technology of such seams, imposed by the current regulatory documents. It is required to ensure reliable isolation of the spent longwall panels by leaving pillars with a width of at least $25 \mathrm{~m}$ in the aspect of providing endogenous fire safety when processing thick shallow seams [17, 18]. At the same time, geodynamic safety is ensured by the use of pliable pillars [19, 20], which are not able to provide such isolation when processing seams prone to spontaneous combustion. It should be noted that there are ways to isolate spent longwall panels [18], however, their implementation is extremely time-consuming, high-cost and technically impossible when mining thick seams.

The application of traditionally used schemes for the preparation of longwall panels by paired drifts with the abandonment of stable pillars is characterized by both an increased dynamic hazard associated with the concentration of stresses in the edge parts of the pillars and an endogenous fire hazard relating to air leaks through the entries. Pliable pillars of coal or the development of seams without leaving pillars have long been used in the conditions of the Alardinskaya mine. However, the use of this technology led to air leaks and an increased risk of spontaneous combustion of coal, as a result of which several endogenous fires arose, the extinguishing of which turned out to be impossible in conditions when the longwall panels were interconnected. Areas of fires were reliably isolated by jumpers, and a wide pillar was left to exclude the connection of existing works in the hazardous area.

\footnotetext{
*Corresponding author: Sidorenkoaa@mail.ru
} 
Further, technological schemes with the abandonment of pillars with a width of more than $30 \mathrm{~m}$ were applied to reliably isolate the spent longwall panels and exclude the air ingress.

The first longwall panel No. 3-30 was taken out without any accidents when working seam reserves 3, leaving wide (more than $30 \mathrm{~m}$ ) pillars; the development of the adjacent longwall panel No. 3-32 with longwall length of $190 \mathrm{~m}$ began (Figure 1). However, the rock bump occurred when the longwall crossed the first diagonal entry. The impact caused the complete destruction of the workings located at the inter-panel pillar, in a section with a length of several tens of meters (Figure 1). The longwall work continued after the workings restoration, but there was another rock bump [19].

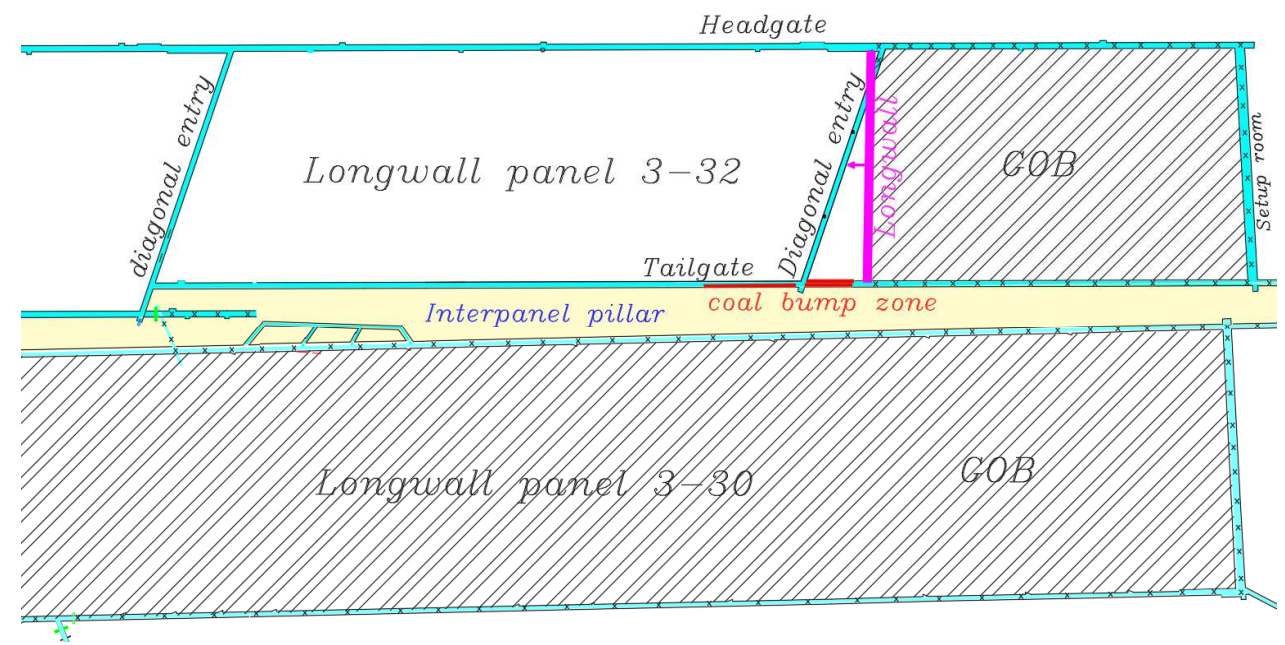

Figure 1. Scheme of mine workings of longwall panels No. 3-30 and 3-32

It should be borne in mind that one of the factors increased the risk of rock bumps was the thickness growth of the strong seam in its main roof when approaching the diagonal panel (Figure 2). An extension of the main roof thickness and strength leads to an enlargement in the step of the main roof collapse and the level of stresses in front of the working face $[25,26]$.

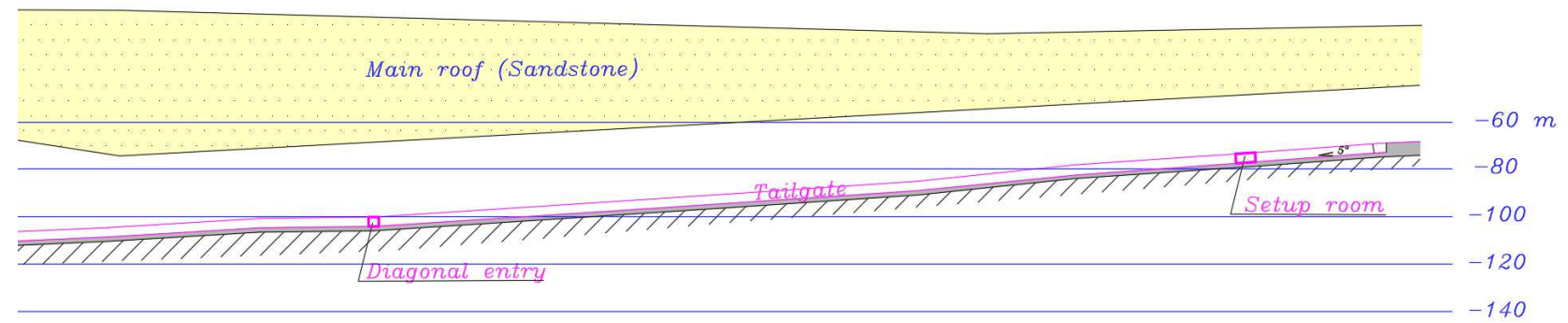

Figure 2. Vertical section along the ventilation drift of the longwall area No. 3-32

The purpose of the research, which results are presented in the paper, was to identify the causes of rock bumps during the development of the longwall panel No. 3-32 at the Alardinskaya mine to elaborate the recommendations eliminating the influence of hazardous factors.

\section{Methods}

The finite element method was implemented in numerical studies. The 3D numerical model was a part of the rock mass around the part of the longwall panel No. 3-32, where the rock bump occurred, and included a coal seam, goaf and a system of mine workings, and the rock layers underlying above and below. The research was carried out using the Ansys Mechanical software package. Methodological approaches applied by other authors were introduced to create the model [21-24].

The calculation was carried out considering the effect of gravity force and the weight of overlying rocks. The depth of mining is $600 \mathrm{~m}$. The shape of the goaf (areas of collapsed rocks) was set due to the angles of rock failure (65 degrees), and the failure zone height was taken equal to six removable seam thicknesses. A feature of the model was consideration of the rocks hovering of the main roof, since its thickness increased in the studied area, which led to a growth of the step and the seam load magnitude in front of the working face [18, 19].

The following rock properties were used in the numerical analysis (Table 1). 
Table 1. Physical and mechanical properties of rocks

\begin{tabular}{|c|c|c|c|c|c|}
\hline Item & Density, $\mathrm{kg} / \mathrm{m}^{3}$ & $\begin{array}{l}\text { Deformation } \\
\text { modulus, hPa }\end{array}$ & $\begin{array}{l}\text { Poisson's } \\
\text { ratio }\end{array}$ & $\begin{array}{c}\text { Coefficient of } \\
\text { adhesion, MPa }\end{array}$ & $\begin{array}{c}\text { Internal } \\
\text { friction angle, } \\
\text { degrees }\end{array}$ \\
\hline Coal seam & 1380 & 2,8 & 0,25 & 1,5 & 23 \\
\hline Host rocks & 2600 & 30 & 0,25 & 12 & 25 \\
\hline Main roof rocks & 2700 & 42 & 0,25 & 15 & 25 \\
\hline Goaf & 2000 & 0,03 & 0,4 & - & - \\
\hline
\end{tabular}

\section{Results and Discussion}

The stress distribution in the three-dimensional model of the rock mass was obtained as a result of numerical analysis (Figure 3). Figure 3 demonstrates that the lowest stress level is observed in the goaf, and the highest in the edge parts of the rock massif and pillars. Such stress distribution is typical for the rock mass in the development of longwalls.

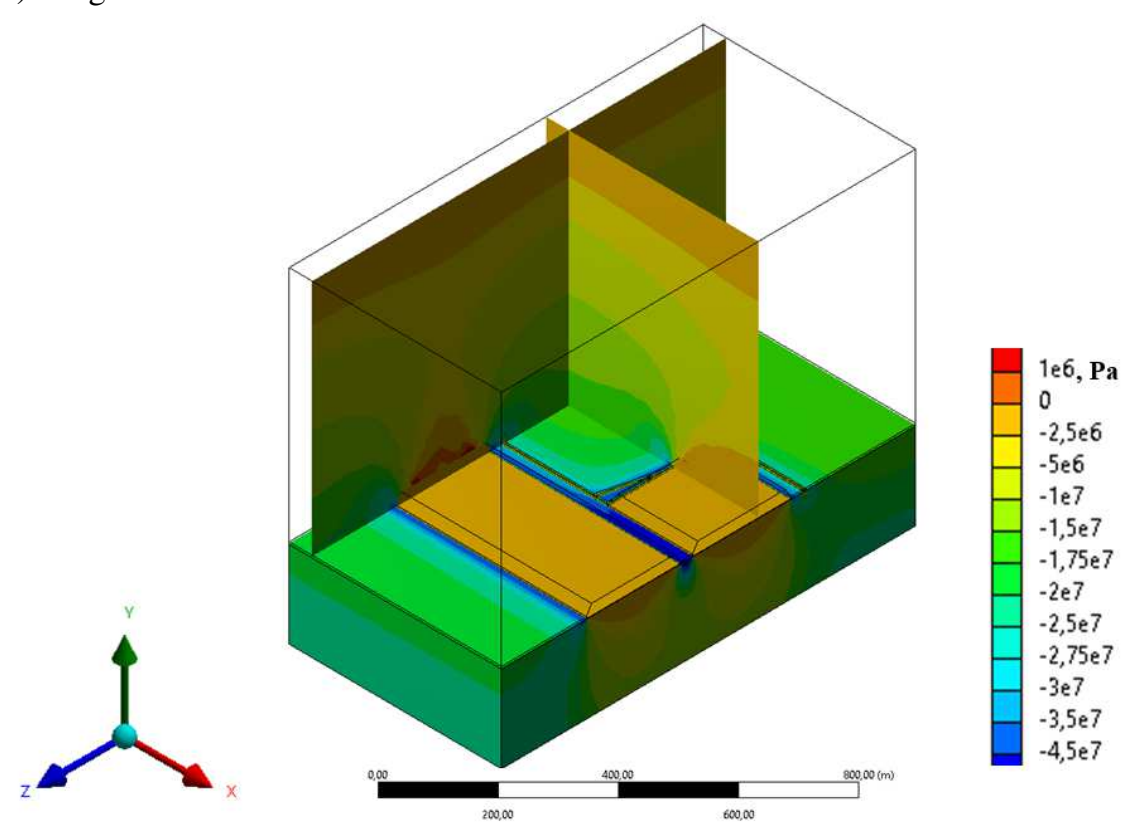

Figure 3. Distribution of vertical stresses in a 3D model

The distribution of vertical stresses in the $\mathrm{XZ}$ plane of the developed seam 3 is of greatest interest (Figure 4). The triangular pillar is formed when the longwall passes the diagonal panel. The stresses in the triangular pillar at the rock bump moment exceeded the stresses in front of the longwall and outside (Figure 4). Stresses in the pillar between the longwall panels No. 3-30 and 3-32 increased with the longwall approaching from 41 to 48 MPa (Figure 4). The maximum stresses in the pillar (55 $\mathrm{MPa}$ ) were observed behind the longwall - between two goaves.

The conducted studies have shown that rock bumps areas (Figure 1) are characterized by the highest stress level (Figure 4). This fact is explained by the influence of the longwall reference pressure 3-32 (in front of the face) and the presence of a triangular pillar, the size of which is gradually decreasing.

Thus, the result of the performed studies was the distribution of stresses in the longwall panels No. 3-30 and 3-32 at the time of a rock bump. The research results confirmed the decisive role of the longwall reference pressure 3-32, the influence of the main roof and the triangular pillar formed during the diagonal entry transition. 


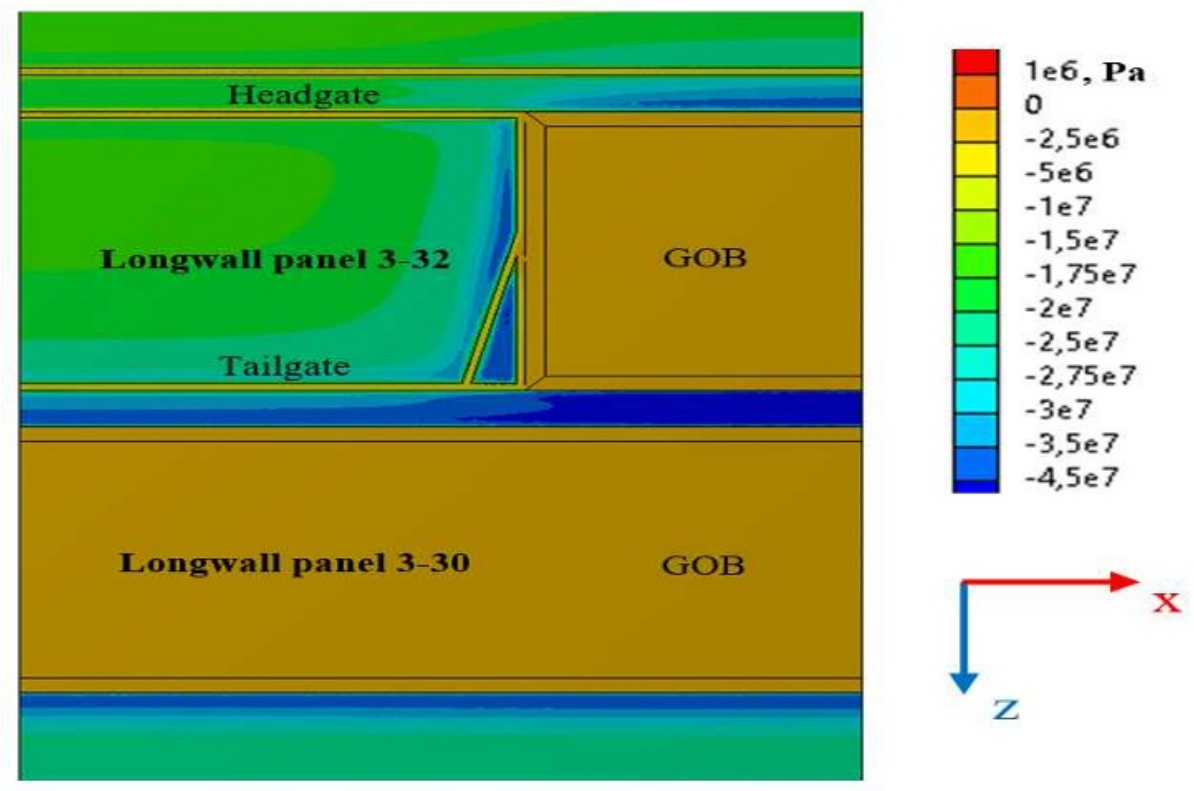

Figure 4. Stress distribution in the seam plane 3

\section{Conclusion}

The development by longwalls of thick coal seams, prone to spontaneous combustion and dangerous to rock bumps, at a depth of $600 \mathrm{~m}$ using technological schemes with coal pillars leaving of $30-40 \mathrm{~m}$ wide, leads to the formation of increased stresses in the pillars and a greater increase when the adjacent panel longwall approaches. The magnitude of stresses in the pillar between the longwall panels No. 3-30 and 3-32 before the longwall approach No. 3-32 was $41 \mathrm{MPa}$ (three times higher than the initial geostatic stress level in the massif), the stresses reached $48 \mathrm{MPa}$ during the approach, and they increased up to $55 \mathrm{MPa}$ after the longwall passage. High stress concentration in the pillar led to an increased risk of rock bumps.

The application of technological schemes provides for the use of diagonal workings, significantly increases the risk of rock bumps due to the gradual decrease in the triangular pillar width, which is formed when the longwall passes the diagonal workings. The stresses in the triangular pillar enhance as its width declines. A rock bump can occur when reaching the pillar width limits. Strong sandstone layers in the seam main roof have a significant effect on the stress level in the reference pressure zone (before the longwall). Hovering of a thick seam layer leads to an increase in stresses by $20-30 \%$. The stresses diminish again after the main roof failure. Thus, the stresses in the reference pressure zone periodically rise and then decline, that is, the reference pressure dynamics is observed.

The performed computer modeling made it possible to establish the distribution of stresses in the rock mass, where rock bumps took place. As a result of the research, it was concluded that the main causes of rock bumps occurred at the Alardinskaya mine are:

- Leaving coal pillars of 30-50 m wide being stress concentrators.

- The use of diagonal workings, when a triangular pillar is formed by longwall during the transition. The stresses increase as the pillar is worked out and the accumulation of compression energy of coal, being sufficient for its dynamic destruction in the form of a rock bump, is possible when the maximum pillar width is reached.

- The presence of thick sandstone layers in the roof leads to the hovering of the underworked layers over large areas with the stress level increase in the reference pressure zone. Periodic enlargement of the sandstone layer thickness leads to the stress level growth.

The following recommendations are given to avoid rock bumps in the conditions of the Alardinskaya mine:

- abandon the application of diagonal entries, which will require the employment of two workings on each side of the longwall panel;

- increase the width between the longwall panels to reduce the stress concentration in the pillars.

The technological scheme currently used in the development of seams that are hazardous to rock bumps in the state of Utah (USA) complies with the specified recommendations [19]. Such a scheme enables the abandonment of a very wide barrier pillar (up to $130 \mathrm{~m}$ ) and allows carrying out two workings on each side of the longwall panel, leaving a pliable coal pillar between them. However, leaving wide pillars of coal leads to an increase in the loss of reserves and requires research aimed at assessing the possibility of reducing the losses. Moreover, the abandonment of wide pillars leads to the formation of heightened stresses zones on adjacent seams [26-28] during the development of coal seam suites, which requires a bundle of works on seams [26].

The course of further research will be associated with the substantiation of technological scheme parameters leaving the system of various flexibility pillars and the rational location determination of mine workings on adjacent seams to ensure the safety of 
mining operations in the conditions of the Alardinskaya mine.

\section{References}

1. S.S. Peng, Longwall mining (London, 2019)

2. Manchao He, Guolong Zhu, Zhibiao Guo, Journal of Rock Mechanics and Geotechnical Engineering, 7(5), 483-492, (2015) doi.org/10.1016/j.jrmge.2015.07.002I.G.

3. I. G. Tarazanov, D.A. Gubanov, Ugol, 3, 27-43 (2021) doi:10.18796/0041- 5790-2021-3-27-43.

4. Jonathon C. Ralston, Chad O. Hargrave, Mark T. Dunn, Journal of Mining Science and Technology, 27(5), 733-739, (2017) doi.org/10.1016/j.ijmst.2017.07.027

5. Guofa Wang, Yongxiang Xu, Huaiwei Ren, International Journal of Mining Science and Technology, 29(2), 61-169, (2019) 1,doi.org/10.1016/j.ijmst.2018.06.005.

6. Jinhua Wang, Zenghua Huang, Engineering, 3(4), 439-444,

(2017), doi.org/10.1016/J.ENG.2017.04.003.

7. N.V. Palyanova, D.A. Zadkov, S.G. Chubukova, Eurasian Mining, 1, 3-5, (2017). doi:10.17580/em.2017.01.01

8. O.I. Kazanin, V.V. Yaroshenko, Journal of Mining Institute. 244, 395-401 (2020). doi:10.31897/PMI.2020.4.1

9. M.L. Rudakov Journal of Mining Institute. 219, 465-471, (2016) doi:10.18454/PMI.2016.3.465

10. C. Wei, C. Zhang, I. Canbulata, A. Cao, L. Dou, Tunnelling and Underground Space Technology. 81, $129-143$

(2018) doi:10.1016/j.tust.2018.07.008

11. Y. Tan, Z. Wang, X. Liu, C. Wang, Journal of the China Coal Society, 46(1), 123-131, (2021) doi: 10.13225/j.cnki.jccs.2021.0010

12. V. Merkulova, Z. Tretyakova, M. Molev, Materials Today: Proceedings. 30, 429-433, (2019)

13. A. Shabarov, A. Kuranov, A. Popov, S. Tsirel, E3S Web of Conferences. 129, 010 (2019) doi: 10.1051/e3sconf/201912901011

14. H. Kang, P. Jiang, Y. Wu, F. Gao, International Journal of Rock Mechanics and Mining Sciences. 142, 104746, (2021). DOI: 10.1016/j.ijrmms.2021.104746

15. V.L.Trushko, O.V. Trushko, D.A. Potemkin, International Journal of Mechanical Engineering and Technology, 9(3), 1038-1045, (2018)

16. D.O. Nagornov, E.A. Kremcheev, D.A. Kremcheeva, International Journal of Civil Engineering and Technology. 10(1), 876-883, (2019).

17. D.D. Golubev, A.A. Sidorenko, Topical Issues of Rational Use of Natural Resources 2019. 1, 3238, (2020). doi:10.1201/9781003014577-5

18. V.I. Klishin, G.Y. Opruk, A.A. Cherepov, Ugol. 9, 56-62, (2018). doi:10.18796/0041-5790-2018$9-56-62$
19. C. Mark, International Journal of Coal Science \& Technolog, 3, 1-9, (2016).

20. K.N. Kopylov, S.S. Kubrin, I.M. Zakorshmenniy, S.N. Reshetniak, Ugol 3, 46-49, (2019) doi:10.18796/0041-5790-2019-3-46-49

21. R. Gu, U. Ozbay, Computers and Geotechnics. 63, 171-182, (2015).

22. S-L. Wang, S-P. Hao, Y. Chen, J-B Bai, X-Y. Wang, Y. Xu, International Journal of Rock Mechanics \& Mining Sciences, 84, 59-68, (2016).

23. Y. Jiang, H. Wang, S. Xue, Y. Zhao, J. Zhu, X. Pang, International Journal of Coal Geology, 95, 20-33 (2012) doi:10.1016/j.coal.2012.02.003.

24. C. Newman, D. Newman, International Journal of Mining Science and Technology, 1, 75-81, (2021) doi:10.1016/j.ijmst.2020.12.020

25. X.S. Liu, X.B. Li, Y.L. Tan, J.G. Ning, D.Y. Fan, Q. Ma, S.L. Song, IOP Conference Series: Earth and Environmental Science. 570 (5) 052010 (2020) doi: 10.1088/1755-1315/570/5/052010

26. C. Mark, F.E. Chase, D.M. Pappas, Proceedings on the New Technology for Ground Control in Multiple Seam Mining, pp. 15-27, (2007)

27. A.M. Suchowerska, R.S. Merifield, J.P. Carter, International Journal of Rock Mechanics and Mining Sciences, 61, 306-320, (2013) doi:10.1016/j.ijrmms.2013.02.009

28. R.K. Zipf, Proceedings of the 24nd International Conference on Ground Control in Mining. pp. 93106, (2005). 